\title{
Study on Construction Quality Management of Expressway Asphalt Concrete Pavement
}

\section{Introduction}

Since the advent of the expressway as a transportation infrastructure, it has been favored by the highway construction industry by virtue of its advantages on transport capacity, speed and safety. With the emergence of new technologies and new craft and the development of China's economy, asphalt concrete pavement that is more suitable for transportation comes into being, which improves the efficiency and safety of transportation, and further promotes the development of society. However, some quality problems on raw materials and construction technology damage to the highway prematurely, which requires that good construction quality management is imminent.

\section{Project Overview}

Yunfu to Zhanjiang section of Shan-Zhan Expressway is a part of "two horizontal" lines of Guangdong highway network planning and the trunk channel from Pearl River Delta to western Guangdong region and southwest region and linking the mainland and Hainan Island. It runs through the three cities of western Guangdong ; its eastern starting point is in Xinxing County of Yunfu City, linking with Qingyuan to Yunfu section of Shan-Zhan Expressway and Jiangmen to Luoding Expressway and providing direct access to northern Guangdong, Foshan, Guangzhou and other Pearl River Delta region; its west end is in Zhanjiang, liking Shen-Hai Expressway and Zhanjiang Expressway and providing direct access to Zhanjiang City and North Bay area of Guangxi Province.

The main structural layer of expressway: $4.5 \mathrm{~cm}$ above layer SBS modified bituminous concrete (GAC-16C), $\quad 5.5 \mathrm{~cm}$ middle layer SBS modified bituminous concrete (GAC-20C), 8cm lower layer bituminous concrete $(\mathrm{GAC}-25 \mathrm{C}),(19 \mathrm{~cm}+19 \mathrm{~cm})$ thick of $4 \% \sim 5 \%$ water-stabilized base, $20 \mathrm{~cm}$ thick of $3 \% \sim 4 \%$ water-stabilized base and $15 \mathrm{~cm}$ thick of cushion layer (graded broken stone). Figure 1 shows the number of roads of a project. Available mechanical equipment: stable pellet mixing equipment, asphalt mix building and base spreading machine, etc.

2. Control the Quality of Pavement Raw Materials and Mixes
Abstract: The highway has been growing with the development of China's economy and among which asphalt concrete pavement is widely used in highway construction with its many advantages such as good slip resistance, durability, surface smoothness, strength, stability and easy maintenance. This paper takes the highway construction of Yunfu to Zhanjiang section of the Shan-Zhan Expressway and branch line of the LM10 contract section as an example to explore the quality of raw materials, construction quality and other aspects of asphalt concrete pavement. It is hoped that it will help to promote the construction quality of asphalt concrete pavement.

Key words:Highway Asphalt concrete pavement Construction quality management

Published on 30th Sept,2017 


\begin{tabular}{|c|c|c|c|}
\hline Engineering site & Structure name & unit & Design Quantity \\
\hline \multirow{14}{*}{ Pavement } & modified asphalt bolt (GAC-16C) & $\mathrm{M}^{2}$ & 32,781 \\
\hline & modified asphalt bolt (GAC-20C) & $\mathrm{M}^{2}$ & 39,713 \\
\hline & Asphalt bolt & $\mathrm{M}^{2}$ & 44,656 \\
\hline & $4 \% \sim 5 \%$ Cement stabilized graded crushed Stone & $\mathrm{M}^{2}$ & 276,190 \\
\hline & $3 \% \sim 4 \%$ Cement stabilized graded crushed Stone & $\mathrm{M}^{2}$ & 179,488 \\
\hline & graded crushed Stone & $\mathrm{M}^{2}$ & 145,511 \\
\hline & Precast C20 Concrete & $\mathrm{M}^{2}$ & 9,358 \\
\hline & Precast C30 Concrete & $\mathrm{M}^{2}$ & 763 \\
\hline & C15 concrete & $\mathrm{M}^{2}$ & 1,314 \\
\hline & C20 concrete & $\mathrm{M}^{2}$ & 18,069 \\
\hline & C25 concrete & $\mathrm{M}^{2}$ & 2,197 \\
\hline & C30 concrete & $\mathrm{M}^{2}$ & 13,815 \\
\hline & C40 concrete & $\mathrm{M}^{2}$ & 57,676 \\
\hline & steel & $\mathrm{t}$ & 2,506 \\
\hline
\end{tabular}

Figure 1: The number of Roads of a Project

\subsection{Control the Quality of} Asphalt Material

The quality of asphalt material is the basis for controlling the asphalt concrete pavement. To ensure its quality, the following need to be done: (1)Study the asphalt material manufacturer and choose the material manufacturer with good reputation and good quality asphalt material;(2) Follow the maintenance specification for asphalt material; Make regular or irregular inspection of asphalt variability and do a rigorous test on asphalt softening point, degree of penetration and penetration and other indicators so as not to affect the performance of the asphalt concrete pavement; (3)Set the long-term storage temperature of asphalt at below 80 to 90 degrees
Celsius with high-quality heavy oil to stabilize the quality of asphalt and slow down its aging; (4)In order to prevent the modified asphalt from stratification, segregation and other changes, it can be placed in the storage tank. This storage tank contains preheating equipment, along with mixing facilities ${ }^{[1]}$.

\subsection{Control the Quality of Aggregates}

High-quality aggregate can effectively improve the overall performance of asphalt concrete pavement, the following can be done to control it quality: (1)Test the structural and processability of coarse and fine aggregates; Good aggregate has the characteristics of no impurities, clean and dry, no weathering, enough strength and good particle shape;(2) Examine the small gravel fields that provide aggregate and choose the best aggregate after comprehensive comparison. As the aggregate produced by different aggregate plants have different quality and specification because the production principles and crusher structures are different, the construction units will use relatively large gravel processing methods to produce aggregate intensively and specifically and use the screen of unified manufacturer to unify the specifications and types of crusher in order to produce high-quality aggregate with uniform specification.(3)The enterprises processing aggregate need to make regular or irregular inspection to key parts such as screen and lining of crushing and 
screening facilities and do timely maintenance. (4)Control the re-breaking rate of crushing to prevent the aggregate's performance from reducing during several crushes. (5)The aggregate needs to be stored on the hardened site after acceptance and ensure to be dry, good drainage and stable foundation to prevent from string and mixing ${ }^{[2]}$.

\subsection{Control the Quality of}

\section{Asphalt Mixture}

To control the quality of asphalt mixture, it shall mainly ensure the stability of its gradation. The following measures can be taken:(1)Separate the aggregate to store and make good protection in rain season; (2)Carry out screen test to and adjust the changed aggregate ratio timely. Secondly, as for storage and transportation, stack aggregate with the method of slope-type layered stacking by bulldozers and transport trucks; the slope is less than 3: 1 and the height can't exceed 4 meters; it shall be noticed that the aggregate can't be discharge along the slope directly. It shall be set partitions in stacked warehouses to avoid mixing. During transportation, it shall move the transport truck to ensure the balance of the mixture and avoid separation. To reduce temperature loss, the mixture also shall be covered. Thirdly, design the asphalt mixture ratio. Strictly control the mixture ratio design of target and production by using Marshall Test mixture ratio to ensure that it meets the technical requirements.

\section{Control the Quality of Asphalt Concrete Backcourt}

\subsection{Selection of Mixing Facilities}

The project uses a stable aggregate mixing plant and an asphalt mixing plant. The selection of mixing facilities needs to ensure that its production capacity shall be in line with the requirements of the scale of the project. The asphalt mixing plant is best able to automatically control the entire process, determine the throughput, analyze the data and mixing quality, and have a secondary dust removal device. Select the ancillary facilities with better performance after determining the mixer, which include loader and asphalt heating equipment, etc. to meet the requirements of asphalt concrete mixing.

The project also uses asphalt concrete production line and uses a brand new DG5000 type asphalt concrete mixer, which mainly contains: cold materials prefabrication and delivery equipment, aggregate drying, heating and screening plant, hot aggregate storage device, powder supply system, asphalt supply system, weighing system and mixing device, dust removal device, heat conduction oil heating device and electrical automatic control system. Most of the parts are installed in the standard container to achieve rapid movement, reduce the cost of relocation and shorten the installation time.

\subsection{Improve the Mixing Process}

It shall be noticed in mixing that: (1)Design mixture ratio;(2)Balance the supply of hot and cold materials prevent from supply delay and overflow; Select the suitable screen aperture and determine the proportion of hot material supply.

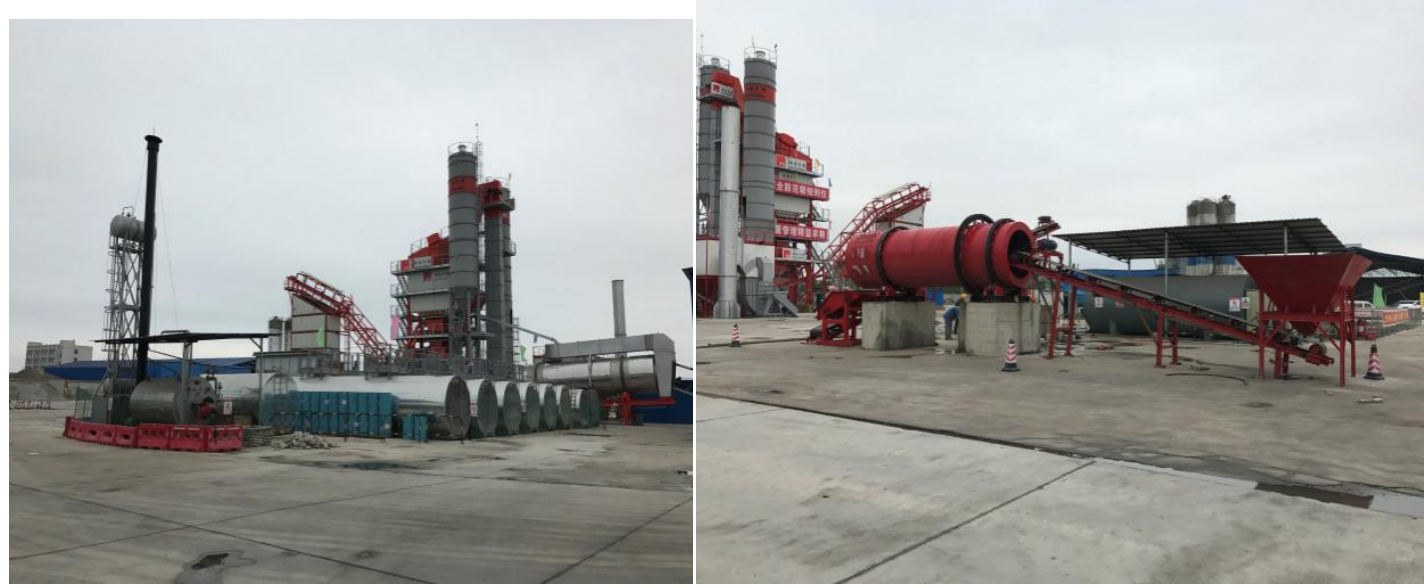




\section{Control the Quality of Asphalt}

Concrete

Construction

Technology

\subsection{Paving Mixture}

It shall be noticed during paving that:

(1)In selecting mixture paver, it shall consider the actual situation of the road, which requires the paver need to have smooth structural parameters and good working performance. This project used seven base pavers. Before using the paver to operate, you need to check it to avoid that the failure of the paver affects the quality of the paving.

(2)According to the scene of the operation, make appropriate adjustment of the paver speed, width and other technical parameters and made adjustment evenly and continuously so as to avoid the separation of the mixture;

(3)The rolling method to be suitable. The project's expressway is two-way four lanes, which can be paved by multi-step ladder way. If synchronous paving has been adopted, it shall use pavers with unified performance and make follow-up improvement to longitudinal seam.

(4)The material mover shall keep the distance from the paver during the paving process and can't brake suddenly when unloading but advance slowly and smoothly, so as not to affect paving speed, which will cause that the pavement looks like washboard.

(5)In the process of paving, if encounters special sections, such as variable slope, amplitude, etc., it shall be noticed firstly that the paver shall be operated smoothly and can't appear sharp turn; Secondly, use one side mobile equalization beam benchmark and cross slope control method to set the leveling benchmark; Thirdly, the operator uses the predictive form control method, which can input the control value cross slope progressively and adjust the gradient appropriately as well. In addition, as for the amplitude section such as toll station, it can use telescopic screed and try to coincide with the paver centerline and each face during the paving. In order to avoid the paver's deviation from the center, you can draw the guide line at the lower deck.

\subsection{Compacted Asphalt Pavement}

The designed mixture and asphalt pavement compaction are two key indicators to extend the service life of pavement. The effect of compaction directly affects the performance of the pavement and the using effect of the mixture, which determines the durability of asphalt concrete pavement to a certain extent. To ensure the quality of compaction of asphalt pavement, it can be done from the following aspects:

(1)The reasonable selection of combination and rolling method shall consider pavement position, climate and mixture's characteristics comprehensively. Usually it will adopt following rolling. The determination of the combination is based on the economics of the final results of the test road. After determining the combination and rolling method, it shall be equipped with compaction machinery; while the quantity shall be determine according to rolling speed and times and paver's speed, etc.

(2)Asphalt mixture rolling temperature control and asphalt mixture pavement compaction degree has a closer relationship. Normally, the rolling temperature is inversely proportional to the viscosity of the asphalt, and the temperature is high and the viscosity is low. If the viscosity of the asphalt is too low, it will make the asphalt mixture flow, the roads after compaction prone to change and crack; And if the viscosity of the asphalt is high, the compaction effect will be not good. So it shall good control on rolling temperature and it can't be too high or too low;

(3) The implementation of rolling needs to be based on a reasonable compaction process and compaction speed. Compaction 
process has three stages, including the initial pressure, pressure and the final pressure, and the construction staff shall strictly follow this procedure for rolling. It can't be rolled for only two stages in order to reduce rolling time and reduce heat loss. Although the shortage of one rolling stage will not move the asphalt mixture and flatness of the road can also be within the specifications of the construction requirements, the rate of crashing of coarse aggregate only going through two-stage rolling will be over $10 \%$, which is much bigger than that going through three-stage rolling. Thus, the rolling can't be stopped until it go through all the three stages.

(4) Rolling speed problem that need to pay attention to. In the actual construction, the rolling speed shall be constant, reasonable and appropriate. The suddenly brake or suddenly start in rolling will move pavement; If the rolling speed is too low, paving and compaction can not be effectively connected, resulting in the quality of compaction can not be guaranteed. On the basis of ensuring the quality of asphalt mixture compaction, the rolling speed is maximized, so that the working efficiency is improved. In addition, the number of rolling is neither too much nor too little and it can be determined by the test.

In recent years, a roadbed pavement intelligent compaction monitoring system has been developed with technical personnel's

exploration

and

combined with information

technology. Its working principle is to use three constellations GNSS positioning module and use network RTK technology roller real-time three-dimensional coordinates to do precise positioning; then microelectromechanical sensor realizes the vibrating state of the roller and non - contact infrared temperature measurement real time monitors the constructing road surface temperature. The collected data is sent to a field or remote data center via a live wireless network or mobile Internet. In the cloud computing center, calculate the rolling state changes of current working face. Do real-time display of compaction data of current working face through mobile terminal and WEB access to timely guide the roller operator to make up for where is short of rolling and avoid over-rolling. The advantages are: ( 1 ) Improved the roadbed quality, extended the service life and reduced the cost of maintenance; (2) Changed the roadbed pavement quality control mode and improved work efficiency; ( 3 ) Improved the acceptance rate of quality and reduced the economic losses caused by reworking quality problems. It has been applied in the construction of Lian-Zhu Expressway and Zhang-Sang Expressway of Hunan Province and the effect is quite good.
5. Do a Good Job at Personnel Allocation and Strengthen Quality Supervision

On the quality management of expressway asphalt concrete pavement construction, personnel configuration and quality control are also important except for raw materials and construction technics. Labor subcontracting and professional subcontracting are the two main forms adopted in actual construction. In order to seek their own interests, some people cut corners, resulting in construction quality does not meet the standard requirements and the completed expressway would soon appear quality issues. The following measures can be taken to prevent the quality problem created by men: (1)Do a good job at personnel allocation and the personnel allocation of a project can been see in figure 3. The staffs of every functional department shall perform their duties. (2)Strengthen the supervision of construction quality. The staffs of safety supervision departments and quality supervision departments should often go to the construction site to check the quality of construction and comment on the problems in the construction. (3) Urge the construction process through activities. For example, this project has launched a spring labor competition and also held "Five Competitions" activity according to the instruction of “"2017 Spring Labor Competition 
Activities Implementation Plan". The theme of the activities is "humanization, specialization, standardization, informatization and elaboration", aiming at "high quality, safety, schedule, efficiency construction quality. and clean governance" and award for a winning project team, which greatly improve the project construction progress and

\begin{tabular}{|c|c|c|c|}
\hline No. & Functional Dep. & unit & No. of staff \\
\hline 1 & Project leader & person & 7 \\
\hline 2 & Engineering Dep. & person & 10 \\
\hline 3 & Safety Supervision Dep. & person & 4 \\
\hline 4 & QC Dep. & person & 15 \\
\hline 5 & Laboratory & person & 12 \\
\hline 6 & Measurement dep. & person & 4 \\
\hline 7 & contract dep. & person & 9 \\
\hline 8 & Equipment and Materials Dep. & person & 3 \\
\hline 9 & Finance Dep. & person & 3 \\
\hline 10 & general office & person & 74 \\
\hline 11 & total & person & \multicolumn{2}{|c|}{} \\
\hline
\end{tabular}

Figure 3 Project Staff Statistics

\section{Conclusions}

With the continuous development of the transport industry, the comfort of the highway has become an important indicator of evaluation. Asphalt concrete pavement can best meet people's needs and is also most widely used. Road construction unit shall do a good job at raw materials, construction technology and other aspects of quality control, constantly innovate the construction technology and improve the quality of highway pavement.

\section{References}

[1]Zheng Bin, Study on Construction Quality Management of Expressway Asphalt Concrete Pavement [J].Jiang Xi Jian Cai,2017(5):143-143.
[2]You Jia, Study on Construction Quality Control of Expressway Asphalt Pavement in New Times [J].Journal of Henan Science and Technology,2013(11):139-140.

[3]Li Guangbo, Study on Quality Control of Expressway Asphalt Concrete Pavement Construction Technology [J].China Science \& Technology Panorama Magazine,2015(10):123-123. 